\title{
SISTEM PENILAIAN KINERJA GURU PADA MI TARBIYATUS SHIBYAN MENGGUNAKAN BOOTSTRAP FRAMEWORK

\author{
Moh. Muslikh ${ }^{1)}$, Retno Wardhani ${ }^{2}$, Nur Nafi'iyah ${ }^{3)}$ \\ ${ }^{1)}$ Mahasiswa Program Studi Teknik Informatika Universitas Islam Lamongan \\ ${ }^{2)}$ Dosen Fakultas Teknik Prodi Teknik Informatika Universitas Islam Lamongan \\ ${ }^{3)}$ Dosen Fakultas Teknik Prodi Teknik Informatika Universitas Islam Lamongan
}

Email :Lionelmucle@gmail.com ${ }^{1)}$, Retzno@yahoo.com ${ }^{2)}$, Mynaff26@gmail.com ${ }^{3)}$

\begin{abstract}
ABSTRAK
Sistem penilaian kinerja guru adalah sistem yang dapat membatu permasalahan penilaian guru di berbagai sekolahan dalam memberikan nilai yang akurat dan tepat sasaran, Salah satunya adalah MI Tarbinyatus Shibyan Kemantren Paciran Lamongan yang menerapkan penilaian kinerja guru untuk mengetahui proses terjadinya pengajaran yang baik dan benar bagi semua siswa dan untuk kenaikan pangkat guru. Penilian kinerja guru sendiri diambil dari empat kriteria yaitu Pedagogik, Sosial, Kepribadian, Profesional empat kriteria ini ada empat belas kompetensi. Oleh sebab itu akan dibuat sistem penilaian kinerja guru berdasarkan langkanya login, isi data guru, isi nilai guru, laporan hasil hasil nilai. Sistem penilaian kinerja guru ini dibuat semudah mungkin, sistem dapat dioprasikan dengan mudah untuk membantu kepala sekolah dalam pemberian nilai yang akurat dan tepat sasaran.
\end{abstract}

\section{Kata Kunci : Sistem penilaian kinerja guru, MI Tarshib}

\section{ABSTRACT}

Teacher performance assessment system is a system that can help the problem of teacher assessment in the schools in in delivering the value of accurate and right on target, one of them is MI Tarbinyatus Shibyan Kemantren Paciran Lamongan which implement the performance appraisal of teachers to know the process of teaching is good and right for all student and for the promotion of teacher. Performance assessment of the teacher themselves were taken from the four criteria, namely Pedagogic, social, personality, there are four criteria of Professional the fourteen competencies. Thus is created the system of teacher performance assessment based on login step, the content of the data content of the teacher, the teacher's grades, report the results of the result value. Teacher performance assessment system is made as easy as possible, the system can be easily dioprasikan to assist the principal in the giving of value accurate and right on target.

\section{Kata Kunci : Sistem penilaian kinerja guru, MI Tarshib}

\section{PENDAHULUAN}

\section{Latar Belakang}

Guru adalah pendidikan profesional yang mempunyai tugas, fungsi, dan peran penting dalam memcerdaskan kehidupan bangsa. Guru yang profesional diharapkan mampu berpartisipasi dalam pembangunan nasional. Selaian itu, agar fungsi dan tugas yang melekat pada jabatan yang fungsional guru dilaksanakan sesuai dengan aturan yang berlaku maka diperlukan penilaian kinerja guru yang menjamin terjadinya proses 
pembelajaran yang berkualitas disemua jenjang pendidikan.

Dengan adanya teknologi pada saat ini, sudah sangat cepat dan maju, salah satunya adalah teknologi di bidang informasi dan telekomunikasi. Kebutuhan manusia terhadap informasi memacu cepatnya perkembangan teknologi di bidang informasi dan telekomunikasi. Kemajuan tersebut salah satunya dapat di wujudkan dalam bidang penilaian. Hal ini dikarenakan bidang penilaian adalah faktor penting dalam mewujudkan terhadap guru. Kemajuan teknologi yang semakin meningkat didukung dengan sarana dan prasarana yang memadai, membuktikan bahwa kini informasi telah menjadi kebutuhan pokok dalam kehidupan manusia. Sehubungan dengan hal tersebut diatas, maka pemakaian komputer di bidang penilaian terutama dalam suatu sistem penilaian memberikan manfaat yang sangat besar, baik dalam ketelitian maupun volume pekerjaan yang ditangani. Sehingga dalam penyajian laporan dan informasi penilaian yang dibutuhkan dapat diperoleh secara cepat, tepat dan lengkap tanpa harus melalui proses pencatatan yang berulang-ulang.

Saat ini teknologi komputer sudah banyak digunakan dalam lingkungan sekolah, tetapi pemanfaatannya secara optimal belum banyak dijumpai di lingkungan sekolah. Pada awalnya sistem penilaian kinerja guru di MI TARBIYATUS SHIBYAN Kemantren yang digunakan masih sangatlah sederhana. Dengan cara manual data yang dihasilkan juga sulit digunakan untuk proses berkelanjutan yang berhubungan dengan penilaian kinerja guru karena akan menghabiskan waktu yang lama jika harus pencari satu persatu data tersebut. teknologi informasi dapat membantu menyelesaikan permasalahan penilaian kinerja guru dengan menciptakan sebuah sistem penilaian kinerja guru menggunakan bootstrap. Proses penilaian dalam sistem ini menggunakan metode penilaian berdasarkan buku "pedoman pelaksanaan penilaian kinerja guru" tahun 2012 oleh kemendikbud, kompetensi yang dipakai meliputi kompetensi pedegogik, kompetensi kepribadian, kompetensi sosial, dan kompetensi profesional. Sistem ini juga melibatkan kepala sekolah dan guru untuk melakukan penilaian di sekolah yang bersangkutan. Oleh sebab itu, pada tugas akhir ini akan dibuat sistem penilaian guru yang dapat mengintegrasikan proses penilaian kinerja guru dalam sebua sekolah.

\section{Tujuan dan Kegunaan Hasil Penelitian}

Tujuan dari penelitian ini yaitu untuk membangun sistem penilaian kinerja guru yang mampuh menghasilkan guru-guru yang berprestasi serta menjadikan guru agar lebih baik kedepanya.

\section{LANDASAN TEORI}

Dalam penelitian ini penulis mengunakan bootsrap untuk membuat sistem sebagai berikut.

\section{Bootstrap}

Bootstrap adalah sebuah library framework CSS yang di buat khusus untuk bagian pengembangan front-end website. bootstrap merupakan salah satu framework HTML, CSS dan javascript yang paling populer di kalangan web developer. pada saat ini hampir semua web developer telah menggunakan bootstrap untuk membuat tampilan front-end menjadi lebih mudah dan sangat cepat. karena anda hanya perlu menambahkan class-class tertentu untuk misalnya membuat tombol, grid, navigasi dan lainnya. Bootstrap telah menyediakan kumpulan komponen class interface dasar yang telah di rancang sedemikian rupa untuk menciptakan tampilan yang menarik, bersih dan ringan. selain komponen class interface, bootstrap juga memiliki fitur grid yang berfungsi untuk mengatur layout pada halaman website yang bisa digunakan dengan sangat mudah dan cepat. dengan menggunakan 
bootstrap kita juga di beri keleluasaan dalam mengembangkan tampilan website yang menggunakan bootstrap yaitu dengan cara mengubah tampilan bootstrap dengan menambahkan class dan CSS sendiri.

\section{Pengertian Penilaian Kinerja Guru}

penilaian kinerja guru adalah penilaian yang dilakukan terhadap setiap butir kegiatan tugas utama guru dalam rangka pembinaan karir, kepangkatan, dan jabatannya. Guru sebagai pendidik profesional mempunyai tugas utama yaitu mendidik,mengajar, membimbing, mengarahkan, melatih, menilai, dan mengevaluasi peserta didik pada pendidikan anak usia dini jalur pendidikan formal, pendidikan dasar, dan pendidikan menengah.

\section{Sistem Penilaian Kinerja Guru}

Sistem penilaian kinerja guru adalah sebuah sistem pengelolaan kinerja berbasis guru yang didesain untuk mengevaluasi tingkatan kinerja guru secara individu dalam rangka mencapai kinerja sekolah secara maksimal yang berdampak pada prestasi peningkatan peserta didik.

\section{Tahap Pemberiana Nilai Guru}

Pada tahap ini penilai menetapkan nilai untuk setiap kompetensi dengan skala nilai 1, 2, 3, atau 4. Sebelum pemberian nilai tersebut, penilai terlebih dahulu memberikan skor 0,1 , atau 2 pada masing-masing indikator untuk setiap kompetensi. Pemberian skor ini harus didasarkan kepada catatan hasil pengamatan dan pemantauan serta bukti-bukti berupa dokumen lain yang dikumpulkan selama proses PK GURU. Pemberian nilai untuk setiap kompetensi dilakukan dengan tahapan sebagai berikut.

Pemberian skor 0,1 , atau 2 untuk masing-masing indikator setiap kompetensi. Pemberian skor ini dilakukan dengan cara membandingkan rangkuman catatan hasil pengamatan dan pemantauan di lembar format laporan dan evaluasi per kompetensi dengan indikator kinerja masing- masing kompetensi. Aturan pemberian skor untuk setiap indikator adalah:

- Skor 0 menyatakan indikator tidak dilaksanakan, atau tidak menunjukkan bukti,

- Skor 1 menyatakan indikator dilaksanakan sebagian, atau ada bukti tetapi tidak lengkap

- Skor 2 menyatakan indikator dilaksanakan sepenuhnya, atau ada bukti yang lengkap.

Tabel 1. Tabel Konversi nilai kinerja ke nilai kompetensi

\begin{tabular}{|l|c|}
\hline Rentang Total skor "X" & $\begin{array}{l}\text { Nilai } \\
\text { Kompetensi }\end{array}$ \\
\hline $75 \%<\mathrm{X} \leq 100 \%$ & 4 \\
\hline $50 \%<\mathrm{X} \leq 75 \%$ & 3 \\
\hline $25 \%<\mathrm{X} \leq 50 \%$ & 2 \\
\hline $0 \%<\mathrm{X} \leq 25 \%$ & 1 \\
\hline
\end{tabular}

5. Perhitungan nilai Kompetensi dan Angka Kredit

1. Nilai Kompetensi

Skor maksimum kompetensi $=$ jumla indikator $\mathrm{x} 2$.

Presentasi $=(($ Total skor $/$ skor maksimum kompetensi)x $100 \%$ ). Nilai kompetensi $=(0 \%<\mathrm{X} \leq$ $25 \%=1 ; 25 \%<\mathrm{X} \leq 50 \%=2$; $50 \%<\mathrm{X} \leq 75 \%=3 ; 75 \%<\mathrm{X} \leq$ $100 \%=4)$.

2. Jumlah Hasil Penilaian/Nilai PKG

Jumlah hasil penilaian adalah Total jumlah nilai kompetensi 1 hingga kompetensi 14 yaitu 56.

3. Konvensi Total Nilai Kinerja Guru ke Skala 100 (PERMENNEG PAN RB NO 16 TAHUN 2009, PASAL 15). Nilai pkg $(100)=($ nilai $\mathrm{pkg} /$ nilai pkg tertinggi) $\mathrm{x} 100$

\section{PEMBAHASAN}

Kriteria-kriteria yang dilakukan dalam membangun sistem penilaian kinerja guru di MI Tarbiyatus Shibyan tersebut mencakup beberapa tahapan yaitu :

1. Pedagogik

2. Sosial

3. Profesional 


\section{Kepribadian}

\section{Analisa Sistem}

Dengan hasil pengamatan yang dilakukan di MI Trabiyatus Shibyan didalam pengelolahan sistem nilai tersebut masih mengunakan pekerjaan administrasi atau tata usaha untuk input nilai secara manual dengan mengunakan :-Microsoft Excel, untuk menyimpan data nilai, hal tersebut mengakibatkan daalam melakukan penilaian karena akan melalui beberapan tahapan baik secara segi penggimputan nilai atau mencetak laporan hasil nilai. Berdasarkan tersebut maka diperlukan suatu sistem untuk memudahkan dalam membantu dan memberikan solusi untuk melakukan penilaian siswa supaya cepat, aman, dan efisien.

\section{Hasil Penilaian PKG}

Perolehan skor untuk setiap indikator pedagogik, sosial, profesional, kepribadian dengan 14 kompetensi tersebut selanjutnya dijumlahkan dan dihitung persentasenya dengan cara membagi total skor yang diperoleh dengan total skor maksimum kompetensi dan mengalikannya dengan $100 \%$. Perolehan persentase skor pada setiap kompetensi ini kemudian dikomversikan ke skala nilai 1, 2, 3, atau 4.

\section{Tabel 2. Tabel Hasil Nilai Kinerja}

\section{Guru}

\begin{tabular}{|c|c|c|}
\hline $\begin{array}{l}\mathbf{N} \\
\mathbf{O}\end{array}$ & KOMPENTENSI & $\begin{array}{c}\text { NIL } \\
\text { AI }\end{array}$ \\
\hline \multicolumn{3}{|c|}{ A. $\quad$ Pedagogik } \\
\hline 1 & $\begin{array}{l}\text { Menguasai karakteristik peserta } \\
\text { didik }\end{array}$ & 2 \\
\hline 2 & $\begin{array}{l}\text { Menguasai teori belajar dan } \\
\text { prinsip-prinsip pembelajaran yang } \\
\text { mendidik }\end{array}$ & 2 \\
\hline 3 & Pengenmbangan kurikulum & 2 \\
\hline 4 & $\begin{array}{lll}\text { Kegiatan } & \text { pembelajaran } & \text { yang } \\
\text { mendidik } & & \end{array}$ & 2 \\
\hline 5 & $\begin{array}{l}\text { Pengembangkan potensi peserta } \\
\text { didik }\end{array}$ & 1 \\
\hline 6 & Komunikasi dengan peserta didik & 2 \\
\hline 7 & Penilaian dan evaluasi & 3 \\
\hline \multicolumn{3}{|c|}{ B. $\quad$ Kepribadian } \\
\hline 8 & $\begin{array}{lrr}\text { Bertindak } & \text { sesuai dengan norma } \\
\text { agama, hukum, } & \text { sosial } & \text { dan } \\
\text { kebudayaan nasional } & & \\
\end{array}$ & 2 \\
\hline 9 & $\begin{array}{l}\text { Menunjukkan pribadi yang dewasa } \\
\text { dan teladan }\end{array}$ & 2 \\
\hline
\end{tabular}

\begin{tabular}{|c|l|c|}
\hline 10 & $\begin{array}{l}\text { Etos kerja, tanggung jawab yang } \\
\text { tinggi, rasa bangga menjadi guru }\end{array}$ & 2 \\
\hline \multicolumn{3}{|c|}{ C. Sosial } \\
\hline 11 & $\begin{array}{l}\text { Bersikap inklusif, bertindak } \\
\text { obyektif, serta tidak diskriminafif }\end{array}$ & 2 \\
\hline 12 & $\begin{array}{l}\text { Komunikasi dengan sesama guru, } \\
\text { tenaga kependidikan, orang tua, } \\
\text { peserta didik, dan masyarakat }\end{array}$ & 4 \\
\hline 13 & $\begin{array}{l}\text { Penguasaan materi, struktur, } \\
\text { konsep dan pola pikir keilmuan } \\
\text { yang mendukung mata pelajaran } \\
\text { yang diampu }\end{array}$ & 2 \\
\hline 14 & $\begin{array}{l}\text { Mengembangkan keprofesionalan } \\
\text { melalui tindakan yang reflektif }\end{array}$ & 3 \\
\hline Jumla (Hasil penilaian kinerja guru) & $\mathbf{3 0}$ \\
\hline
\end{tabular}

Nilai total ini dikonversikan ke dalam skala nilai sesuai Peraturan Menteri Negara Pendayagunaan Aparatur Negara dan Reformasi Birokrasi No. 16 Tahun 2009. Konversi ini dilakukan dengan menggunakan rumus sebagai berikut.

Nilai PKG (skala 100 (Nilai PKG)

/(Nilai PKG Tertinggi) $\times 100$

$$
\begin{aligned}
& =\frac{30}{56} \times 100 \\
& =53 \%
\end{aligned}
$$

Tabel 3. Tabel Konversi Nilai Kinerja PK GURU ke Presentase

\begin{tabular}{|c|c|c|}
\hline $\begin{array}{c}\text { Nilai Hasil } \\
\text { PK GURU }\end{array}$ & Sebutan & Persentase \\
\hline $91-100$ & Sangat Baik & $100 \%$ \\
\hline $76-90$ & Baik & $80 \%$ \\
\hline $61-75$ & Cukup & $70 \%$ \\
\hline $51-60$ & Sedang & $50 \%$ \\
\hline$\leq 50$ & Kurang & $25 \%$ \\
\hline
\end{tabular}

Nilai yang diperoleh Moh. Aris Afandi, memperoleh nilai kinerja "Sedang", bagi guru-guru yang hasil penilaian kinerjanya masih berada di bawah standar kompetensi $(<=60)$ atau dengan kata lain berkinerja rendah diwajibkan mengikuti program pengembangan keprofesian berkelanjutan (PKB) yang diorientasikan untuk mencapai standar tersebut; sementara itu bagi guru-guru yang telah mencapai standar kompetensi (>60), kegiatan PKB-nya diarahkan kepada peningkatan keprofesian agar dapat memenuhi tuntutan ke depan dalam pelaksanaan tugas dan kewajibannya sesuai dengan 
kebutuhan sekolah dalam rangka memberikan layanan pembelajaran yang berkualitas kepada peserta didik.

\section{Perancangan Proses}

Perancangan proses merupakan tahap mempersiapkan implementasi sistem baru, menggambarkan sistem baru, mengatur dan merencanakan elemen-elemen yang terpisah kedalam satu kesatuan yang utuh, serta mengkonfigurasikan perangkatperangkat yang dibutuhkan dalam perancangan sistem baru.

\section{a. Data Flow Diagram Level 0}

Data flow diagram adalah gambaran dari sistem yang telah ada atau sistem baru yang akan dikembangkan. Berikut adalah gambaran data flow diagram sistem penilaian kinerja guru di MI Tarbiyatus Shibyan Kematren :

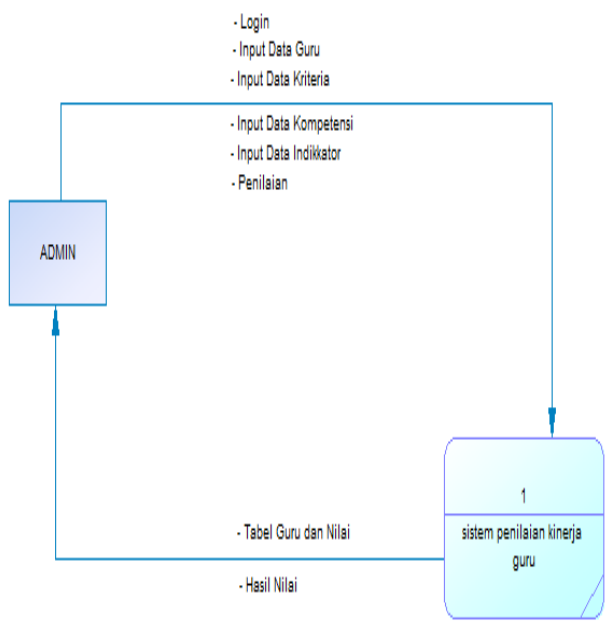

Gambar 1. Gambar DVD Level 0

Pada gambaran diatas terdapat satu aktor utama yaitu admin. Admin bertugas untuk mengoprasikan dan mengimputkan data-data yang dibutuhkan saat pembuatan sistem seperti kriteria yang digunakan, Pedagogik, Sosial, Profesianal, Kepribadian yang dihasilkan.

\section{b. Data Flow Diagram Level 0}

Adapun pengembangan dari DVD level 0 diatas ditransformasikan kedalam bentuk DFD Level 1 dengan tujuan untuk mempermudah pengambilan keputusan bagi penulis dalam perancangan awal perangkat lunak (program) yang akan dibuat.

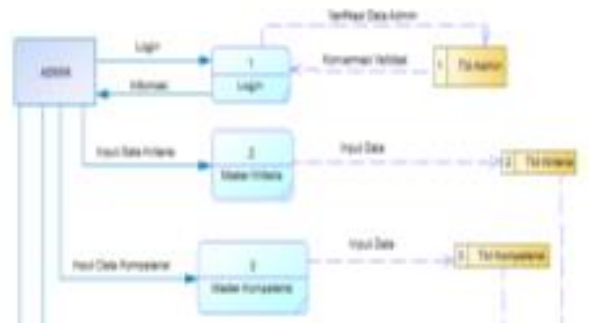

\section{Gambar 2. Gambar DVD Level 1}

4. Perancangan Basis Data

a. Conceptualy Data Model (CDM)

CDM dipakai untuk menggambarkan secara detail struktur basis data dalam bentuk logik. CDM terdiri dari objek yang tidak diimplementasikan secara langsung kedalam basis data yang sesungguhnya.

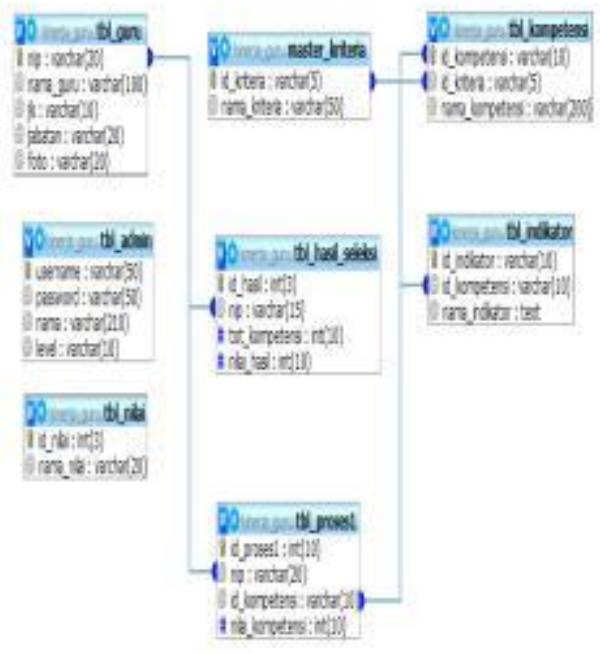

\section{Gambar 3. Gambar Conceptualy Data Model (CDM)}

\section{Rancangan Antarmuka / Interface}

Rancangan antarmuka adalah gamabaran sistem yang dibuat teutama menu utama tampilan sistem.

Berikut ini adalah rancangan form yang akan digunakan pada sistem penilaian kinerja guru.

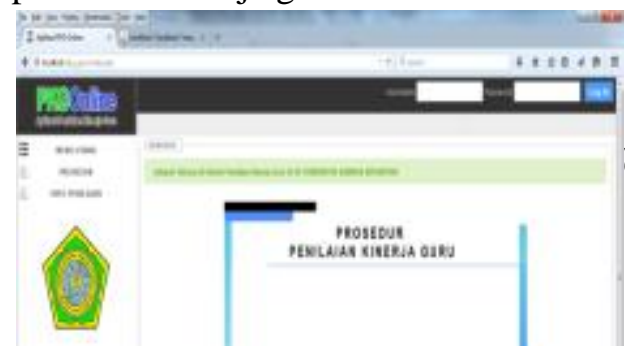




\section{Gambar 4. Gambar Form Menu Utama}

Keterangan :

1) Tombol Prosedur fungsinya untuk melihat prosedur apa saja yang ada dalam penilaian guru.

2) Tombol info penilaian fungsinya untuk melihat data kompetensi.

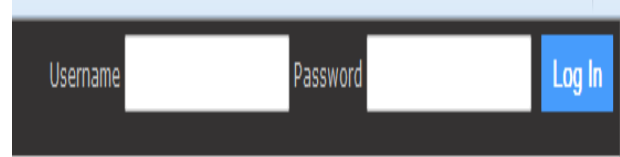

Gambar 5 Gambar Form Login

Keterangan :

1) Username dan password fungsinya untuk memasukan inputan saat login.

2) Long in berfungsi untuk menjalankan perinta.

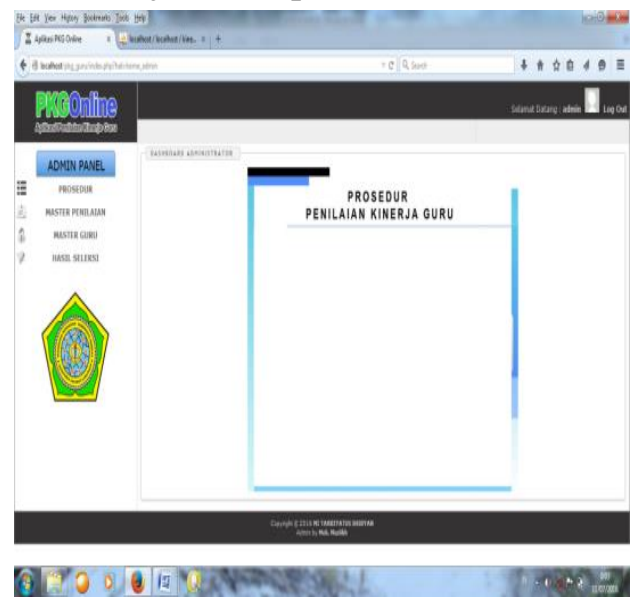

Gambar 6. Gambar Form Menu

Keterangan:

Terdapat menu Prosedur, Master penilaian, yaitu menu yang berisi 3 yang terdiri dari master kriteria, master kompetensi, dan master indikator. Master guru

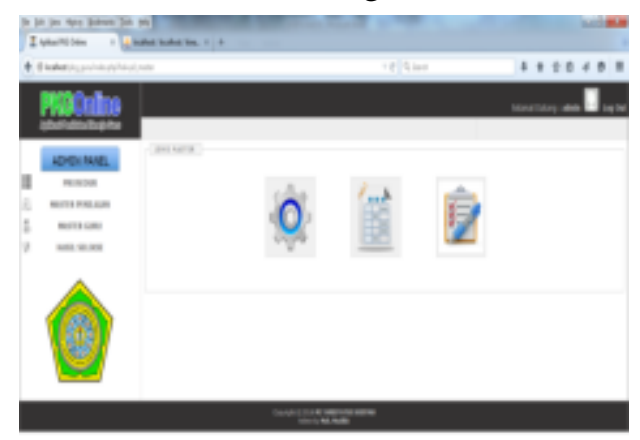

Gambar 7. Gambar Master Penilaian

Halaman master berisi 3 sub-menu yaitu master kriteria, master kompetensi dan master indikator. Dimana masingmasing memiliki kriteria dan bobot nilai masing-masing.

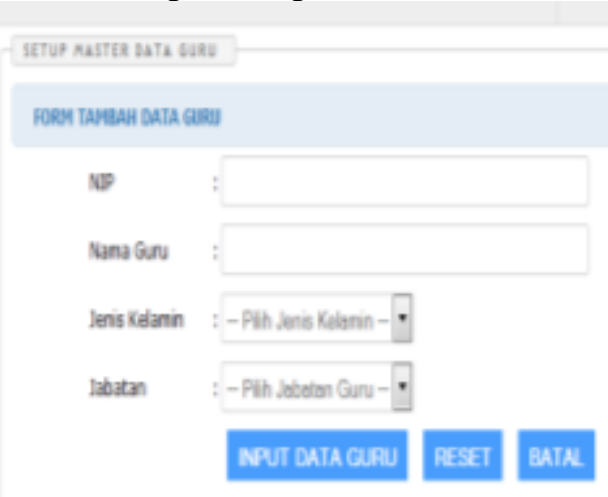

\section{Gambar 8. Gambar Form Input} Nama

Pada halaman ini berisi inputan guru yang akan dimasukan. Interface halaman Input Guru.

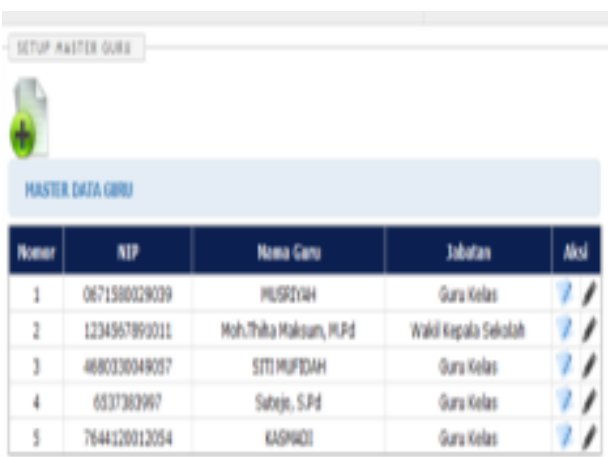

Gambar 9. Gambar Form Data Guru

Pada halaman ini berisi data guru yang akan dimasukan. Interface halaman Input Guru.

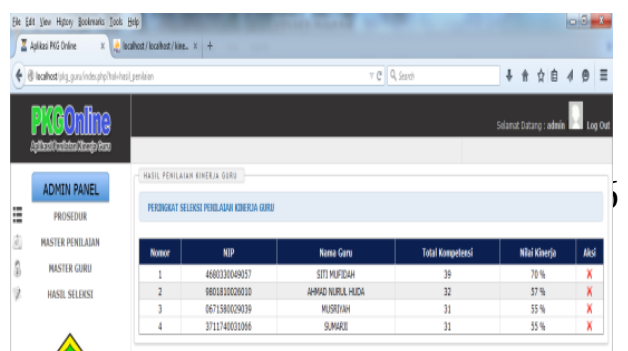




\section{Gambar 10. Gambar Form Hasil \\ Nilai}

Pada halaman ini berisi hasil nilai guru yang akan dimasukan. Interface halaman Input Guru.

\section{KESIMPULAN}

Berdasarkan pembahasan yang telah dijabarkan oleh penulis pada babI sampai bab V.

1. Dengan adanya system ini, maka kinerja kepalah sekolah MI Tarbiyatus Shibyan Kemantrenpetugas akan menjadi efektif dan efesien.

2. Untuk membuat suatu sistem penilaian maka sutau sistem harus terkoneksi dengan database yang fungsinya untuk menyimpan datadata yang akan ditampilkan di sistem.

\section{DAFTAR PUSTAKA}

Buku-2-Pedoman-pkg. Home page Online Avilable from http://www.ekinerjaguru.org; Internet; accessed July 2012.

Fatansyah, Ir, 1990. "Basis Data”, CV. Informatika Bandung.

Kadir, Addul, 2010. Mudah Mempelajari Database MySQL. Yogyakarta : Andi.

Kementrian pendidikan dan Kebudayaan, Pedoman Pelaksanaan Penilaian Kinerja Guru, Jakarta, 2012. 